\title{
A Study on Self Regulation Techniques Training Towards Achievement of Students' HRV
}

\author{
Muhammad Nubli Abdul \\ Wahab \\ Centre for Modern Language \& \\ Human Sciences, University \\ Malaysia Pahang, \\ Lebuhraya Tun Razak, 26300, \\ Gambang \\ Pahang, Malaysia
}

\author{
Wan Rusyaini Wan Mohd \\ Centre for Modern Language \& \\ Human Sciences, University \\ Malaysia Pahang, \\ Lebuhraya Tun Razak, 26300, \\ Gambang \\ Pahang, Malaysia
}

\author{
Azham Abdul Rahman \\ Centre for Modern Language \& \\ Human Sciences, University \\ Malaysia Pahang, \\ Lebuhraya Tun Razak, 26300, \\ Gambang \\ Pahang, Malaysia
}

\begin{abstract}
This experiment was about the implementation of self regulation techniques training in order to achieve the targeted HRV score. 20 secondary school students at the age of sixteen were chosen for this experiment. The students involved were known to have some behavioral problems. The experiment was to observe and study the importance of self regulation within the students in order to achieve the required HRV score. The students were taught and instructed to perform resonant breathing and dzikr recitation. Both were the self regulation techniques implemented for the experiment. A biofeedback device was used to monitor the changes in the students' HRV as the experiment progressed. At the end of the experiment, it clearly showed the importance of self regulation in order to achieve the HRV score and thus changes in behaviors.
\end{abstract}

\section{Keywords}

Self regulation, slow/resonant breathing, 'dzikr', biofeedback, heart rate variability (HRV).

\section{INTRODUCTION}

\section{Self Regulation}

Self regulation can be defined as the capacity to control one's impulses, both to stop doing something, if needed (even if one wants to continue doing it) and to start doing something, if needed (even if one doesn't want to do it).[1] It is the ability to act in a long-term best interest, consistent with one's deepest values. (Violation of one's deepest values causes guilt, shame, and anxiety, which undermine well being.) Emotionally, self-regulation is the ability to calm oneself down when feeling upset and cheer up when feeling down.[2] Self regulation is considered as a skill. Being a skill, it could be improved by learning and training. In order to improve self-regulation skill, a good place to start is an understanding of the biology and function of emotions in general and specifically feelings. Emotions move humans. The word, "emotion," derived from the Latin, literally means "to move." The ancients believed that emotions move behavior; in modern times it is said that emotions motivate behavior. They energize us to do things by sending chemical signals to the muscles and organs of the body; they prepare us for action.[2] It means that the self regulation skill needs to be mastered in order to achieve great things in life and emotions play a crucial role in mastering the said skill.

Self regulation can be divided into a few classes, that are closely related to this experiment:

$\begin{array}{ll}\text { - } & \text { Emotional self-regulation } \\ \text { Homeostasis, in systems theory }\end{array}$

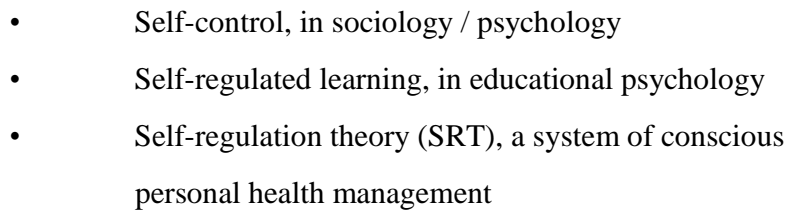

The following are brief descriptions of each of the different classes:

Emotional self-regulation or regulation of emotion is the ability to respond to the ongoing demands of experience with the range of emotions in a manner that is socially tolerable and sufficiently flexible to permit spontaneous reactions as well as the ability to delay spontaneous reactions as needed.[4] It can also be defined as extrinsic and intrinsic processes responsible for monitoring, evaluating, and modifying emotional reactions.[5] Emotion self-regulation belongs to the broader set of emotion-regulation processes, which includes the regulation of one's own feelings and the regulation of other people's feelings.[6]

Homeostasis, also spelled homoeostasis (from Greek: ö $\mu$ oro

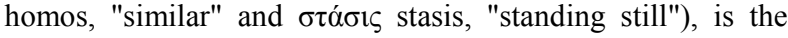
property of a system in which variables are regulated so that internal conditions remain stable and relatively constant. Examples of homeostasis include the regulation of temperature and the balance between acidity and alkalinity $(\mathrm{pH})$. It is a process that maintains the stability of the human body's internal environment in response to changes in external conditions.[1]

Self-control is the ability to control one's emotions, behavior, and desires in the face of external demands in order to function in society.[7] In psychology it is sometimes called self-regulation. Self-control is essential in behavior to achieve goals and to avoid impulses and/or emotions that could prove to be negative.[8] In behavior analysis self-control represents the locus of two conflicting contingencies of reinforcement, which then make a controlling response reinforcing when it causes changes in the controlled response.[9][10]

Self-regulated learning (SRL) is learning that is guided by metacognition (thinking about one's thinking), strategic action (planning, monitoring, and evaluating personal progress against a standard), and motivation to learn.[11] "Selfregulated" describes a process of taking control of and evaluating one's own learning and behavior.[12] Selfregulated learning emphasizes autonomy and control by the individual who monitors, directs, and regulates actions toward goals of information acquisition, expanding expertise, and self-improvement" [13] 
Self-regulation theory or SRT is a system of conscious personal health management. Self-regulation includes impulse control, the management of short-term desires. People with low impulse control are prone to acting on immediate desires. This is one route for such people to find their way to jail as many criminal acts occur in the heat of the moment. For nonviolent people it can lead to losing friends through careless outbursts, or financial problems caused by making too many impulsive purchases. Although a doctor may give a patient sound medical advice, the theory states that only with selfregulation will the patient appropriately implement that advice. For medical treatment to be effective, the patient needs to be interested in improving one's own health.[3]

An individual who manages to self regulate him/herself is known as a self regulated person. A previous study has revealed that a higher self regulated person exhibited high self-efficacy, had strategies in learning and finally achieved good performance. [14] Self-regulated students have higher motivation. From that particular self value, they implemented a better learning strategies with their own initiatives and respond actively on any situational demands.[15] Selfefficacy in an important value in self-regulation. Self-efficacy is defined as an individual's belief in his or her capacity to execute behaviors necessary to produce specific performance attainments [16] Self-efficacy reflects confidence in the ability to exert control over one's own motivation, behavior, and social environment. It has also been reported that selfregulation is an important elements in goal-setting, planning, executing, managing, monitoring and self-evaluating [17] It brings a meaning that self-regulation influences motivations, thoughts, emotional states and patterns of behavior among individuals.

In this experiment, the students involved were instructed to perform slow breathing or resonant breathing. While executing the breathing exercise, the students were requested to recite dzikr, an Islamic chanting. They were instructed to do the chanting while exhaling. The breathing exercise and dzikr reciting were the self regulation technique training imposed for this experiment. The ability to follow instructions and regulate themselves was the key factor in this experiment.

\section{METHOD}

The objective of this experiment was to analyze the effects of self regulation techniques training to students' HRV readings. The techniques being implemented were resonant breathing and $d z i k r$ recitation. 20 students were involved in the experiment. The students' responses were based on their biofeedback responses, the HRV readings. The main biofeedback equipment being used in the experiment was emWave desktop Software Kit devices, to detect their emotion through their heart rate rhythm. The same equipment was also being used in an experiment involving HRV done before. [18]

The students were divided into two groups, based on their academic background in which 10 of them with low academic performance and 10 students with good academic performance in the final examinations. The samples were selected based on their academic performance gathered from the School Education Analysis System (Sistem Analisa Pendidikan Sekolah - SAPS), which is an analysis for students' advancement in the examinations. . It is a centralized system to accumulate all relevant information about the examinations, in order to accommodate the process of storing the students' current examinations data. It is also to enable the scrutiny of the data by relevant authorities and parents.

During the biofeedback training in the clinical-experiment, it was done with blind-test. It meant that the students were randomly picked and their self regulation would be examined without knowing their academic background. This method was being applied in order to avoid the researcher from being biased while executing the communication script stimulation. So, the students were only exposed to the script by the researcher during the clinical-experiment.

By using the ear-clip sensor to investigate the samples' HRV, they underwent the four procedures of biofeedback training protocols; baseline, pre-recorded zikr, self zikr and self-talk stimulation. (see Figure 3.7). They were seated on a comfortable back rest chair, in a quiet and air-conditioned room. This comfortable environment was important in order to make sure that the students were in a good mood and became calm throughout the session without any disruption and disturbance of uncomfortable situations that might affect their emotion. The disruption in their emotion will automatically affect their heart rate and this would make some changes in the data being recorded during the training.[20]

A 12 inch laptop was set up in front of the students showing the pattern of their heart rhythm, the coherence ratio indicating VLF (red colour), LF (green colour) and HF (blue colour) (see Figure 3.9). The students were provided with a monitor showing their level of heart rate. They were encouraged to achieve 100 per cent LF coherence while undergoing the training through breathing technique and selfzikr stimulation.

Being one of the self regulation techniques, slow breathing exercise was implemented, whereby each student was instructed to execute their breathing accordingly. They were told to inhale deeply for 3 seconds and exhale fully for7 seconds. This particular breathing is called Resonant Breathing. It is slow breathing, (around 3-7 breaths per minute) and relaxed abdominal breathing that can produce a unique state of balance in the autonomic nervous system and resonance or communication between body systems that are connected to breathing.[19]

Before the experiment started, these following items must be made available: information)

2. Guardian's and student's consent form (permission from parents and student)

3. Student's objective form (student's aspirations)

4. Nijmegen Questionnaire (student's physical health conditions)

Before the experiment commenced, the information and data about the students must be obtained. The physiological status of the students must be good, so that it would not influence the results. At this stage also, all the relevant forms must be completed. While doing that, the researcher tried to create a friendly environment with the students and tried to make the students felt comfortable. These were the phrases used by the researcher:

"Allow your arms to feel heavy and relaxed. Visualize relaxing at the beach on a warm, bright 
day. You are in a comfortable recliner chair. No one is close by. All you hear are the waves lapping at the shore and sea gulls in the distance. You may feel your hands warming".

act as baseline or reference for the next procedures. After the end of this first session (baseline reading 1), the students should know their actual heart performance at this state based on the readings of the coherent ratios (red, blue and green bars). The following is the script used:

"I want you to clear your mind, Concentrate fully on this session. Imagine that you are now alone on an island, so peaceful and soothing".

"I want you to forget all the problems in your mind. Now, it is just you and I. You may begin your diaphragm breathing."

"Relax..."

"Okay. Let's begin the session now."

The next stage was to get the basic HRV readings of the students. These readings would act as a baseline for next experiments. Three minutes was allocated to take the HRV readings of each student. The HRV sensor was attached to the student's ear. After briefly explaining the device to the student, the 'start' button was pressed and the student's HRV reading was taken for three minutes. These readings would act as baseline or reference for the next procedures. After the end of this first session (baseline reading 1), the students should know their actual heart performance at this state based on the readings of the coherent ratios (red, blue and green bars). The following is the script used:

"I want you to clear your mind, Concentrate fully on this session. Imagine that you are now alone on an island, so peaceful and soothing".

"I want you to forget all the problems in your mind. Now, it is just you and I. You may begin your diaphragm breathing."

"Relax..."

"Okay. Let's begin the session now."

The next stage of the experiment was pre-recorded $d z i k r$ recitation. The pre-recorded $d z i k r$ session took 3 minutes. The students were asked to listen and recite the "La ilaha illa Allah" $d z i k r$ by following the pre-recorded $d z i k r$ from the voice recorder. The $d z i k r$ was recited in fast pace while the diaphragm breathing technique demonstrated slow pace of breathing which was to achieve 6 breaths per minute. The contrast in the pace rhythm between pre-recorded $d z i k r$ and diaphragm breathing technique would measure their effort in finishing a difficult task. The following is the script being used:

"Now, I want you to clear your mind and focus towards getting $100 \%$ LF coherence. Try to relax and ease yourself, inhale and exhale slowly. Inhale... 1,2,3.4 exhale 5,6,7,8,9,10,11. (script being repeated)

"Inhale... 1,2,3.4 exhale 5,6,7,8,9,10,11" (repeated 3 times).

"I want you to recite $d z i k r$ in your heart along with the pre-recorded $d z i k r$ that I am going to play soon. While reciting the $d z i k r$ in your heart, do your breathing the right way"
"If your coherent reading is decreasing, keep on with your diaphragm breathing and $d z i k r$ reciting until the reading increases back. Do your best, increase the coherent readings and maintain it as long as possible."

"We start now with the "La ilaha illa Allah" dzikr.

The third protocol was the self- $d z i k r$ which allowed the sample to recite the La ilaha illa Allah dzikr with his/her own initiative at own pace, without being forced. However, the targeted goal remained the same which was to achieve the $100 \% \mathrm{HF}$ coherence score in the power spectrum. The students were asked to recite the inner self-dzikr quietly for 3 minutes. After 3 minutes, they were asked to stop.

"Now, I want you to recite dzikr in your heart on your own while looking at the screen in front of you, that is showing your coherent readings. Try to increase your coherence and maintain it as long as possible. If it decreases, continue doing your diaphragm breathing until it reaches the LF coherence."

The next protocol was the self talk protocol. Before the protocol started, the sample was being stimulated by a selftalk script. After 30 seconds reciting the dzikr, the sample was being exposed to the self-talk script. The script was as follows:

"Just now, you have seen your coherence results. Take a little bit more time for yourself to really internalize the dzikr."

Now ... I want you to keep on concentrating on La ilaha illa Allah. I know that you could improve your coherent score. Clear your mind, concentrate fully on the session. Forget all your problems, push them aside! Just do your best with the dzikr . Concentrate fully on the phrase. Believe that you can get the $100 \%$ LF coherence. I believe you could!

Again... try to relax, inhale and exhale slowly. Now, place your palm on your stomach. Try to feel the slow flowing air into your lungs, to your brain, throughout your whole body..

Inhale.... Exhale slowly... We do it again. Inhale...... Exhale slowly.... (twice). Now recite dzikr in your heart ... La ilaha illa Allah... (low and long intonation). Keep on reciting La ilaha illa Allah...(twice)."

"Try to internalize La ilaha illa Allah with feelings of repentance ... with humility... as a servant to the Almighty Creator."

"Imagine that you are now in front of Allah swt. (pause) Lower your gaze in front of the Almighty with feelings of repentance."

"Whisper in your heart ... O, Allah, I have been negligent in remembering you. I have been unfair and untrue to myself, dear Allah. Help me back to Your Path, O Allah

Listen to my confession, a sinful servant, You are the Most Great. La ilaha illa Allah... There is nothing worthy of worship except You (Pause). 
Keep on reciting "La ilaha illa Allah" in your heart until I give you the signal to stop. Keep on recitingr... "La ilaha illa Allah..."La ilaha illa Allah

Once in a while, look at your coherent score. Try to increase it. Breathe slowly and continue your dzikr...

"La ilaha illa Allah...."La ilaha illa Allah...

\section{RESULTS}

$\mathrm{GAP}=$ good academic performance LAP $=$ low academic performance

Figure 4.1 shows the results of $t$-test for mean values in the Baseline the coherence score in the VLF, LF and HF during the clinical experimental test. The bar chart indicates that the GAP has the highest score $(m=68.5)$ in the LF coherence score compared to the LAP $(m=64.4)$ in the Baseline protocol. Meanwhile the VLF ( $m=15.2$ for the GAP; $m=19.4$ for the LAP) protocol between academic performances. The results compared and HF scores ( $m=16.3$ for GAP; $m=16.2$ for LAP) were low in both group of academic performance.

Figure 4.2 illustrates the comparison between VLF, LF and HF coherence score during the Pre-recorded dzikr protocol. It indicates that the good academic performance (GAP) have highest LF coherence score $(\mathrm{m}=53.3)$ compared to the low academic performance (LAP), $\mathrm{m}=42.7$. The higher result in the LF for the GAP students was parallel with the previous study [21], which stated that positive emotional would affect behavior in terms of efforts and persistence. The GAP students were reported to plan strategy to improve performance [22]. Meanwhile in the VLF coherence score, LAP students $(\mathrm{m}=41.5)$ indicated higher score compared to the GAP students $(m=26.4)$. However, the HF score for LAP $(m=15.8)$ and GAP $(m=19.3)$ students were at the lowest. The lowest score in the LF for LAP indicated that these groups failed to achieve $100 \%$ LF in the Pre-recorded Dzikr protocol as the targeted goal in the clinical experiment.

Figure 4.3 illustrates the comparison on the mean values in the Self-Dzikr protocol for GAP and LAP students. It was indicated that the VLF for LAP $(m=54.6)$, was the highest score compared to the GAP $(\mathrm{m}=21.8)$ during the Self-Dzikr protocol. Meanwhile, in the LF coherence score, it was indicated that the GAP students had higher score $(\mathrm{m}=36.4)$ compared to the LAP students $(m=25.7)$. It also indicated the same result where the GAP students had higher score $(m=33.5)$ compared to the LAP students $(m=28)$ in the HF coherence score. The higher results in the HF might be due to some intentional task, mild stress, a cognitive reaction on orienting response and reduction in parasympathetic cardiac control [23][24]. Again, in the self-dzikr protocol, the LAP students failed to achieve the highest scores in the LF coherence scores which showed that they were not selfregulated to achieve the targeted goal successfully. This indicated that when the samples loose control on the targeted goal, the response for the frequency in the VLF scores becomes higher [25]. The higher VLF coherence score by the
LAP students were also supported by Kuhl and Kraska in their research[26], which indicated that the low performance students have poor self-regulation attitude towards given tasks. Meanwhile, they found that high-IQ children were able to pay attention on the instructions to be followed towards targeted goal.

Finally, the students underwent the Self-Talk protocol which demonstrated that the GAP students have the highest coherence score in the LF $(m=73.9)$ compared to the LAP $(m=51.6)$. It was illustrated in Figure 4.4, which showed the comparison of the mean values among LAP and GAP.

In the Self-Talk protocol, the coherence score for VLF indicated that the GAP have lower score $(\mathrm{m}=15)$ compared to the LAP $(\mathrm{m}=27)$. Meanwhile the HF coherence score for the GAP students was lower $(m=11.1)$ compared to the LAP students $(m=17.4)$. Finally, in the Self-Talk protocol, the LAP students totally failed to self-regulate themselves in achieving the $100 \%$ LF coherence score. This indicated that the LAP students have low effort, motivation and self-regulation in terms of achieving goal in the task given.

As a summary, the LAP students failed to achieve $100 \%$ LF coherence scores in all protocols which indicated that they are non-self regulated individuals in order to finish the task successfully. They have higher results in the VLF coherence score. As were investigated in the previous study on the effectiveness of self-relaxation, the six breaths per minute and reciting dzikr during the biofeedback training and techniques, the VLF coherence score should decrease parallel with the increment in the LF score [27]. It showed that they failed to implement the biofeedback training where they easily gave up to achieve the targeted goal by failing to apply the method to increase the scores in the LF.

However, the GAP students successfully achieved the targeted goal during the clinical experiment which indicated that they have put their full effort, high motivation and followed the instructions to achieve the $100 \% \mathrm{LF}$ coherence score. The higher results in the LF coherence score was related to the sympathetic cardiac control and a decrement in the parasympathetic control, sometimes involved both, as a sign of stress [24]. The results obtained from the clinical experiment were consistent with a previous study [28 GAP students. It was reported that the goal orientation would make them become proactive, have the ability in problem solving and could easily adapt to the new environment [29]. The findings are positively consistent with this study, in terms of self-regulation by investigating their performance during the protocols.

This self-regulatory persistence was parallel with the previous research which also revealed that persistence while finishing the given task was an indicator to measure selfregulation/control [30]. It was because various kinds of difficulties will test their self-control on how persistent they were while undergoing the protocols. Thus, the self-regulated student could be concluded as persistent 


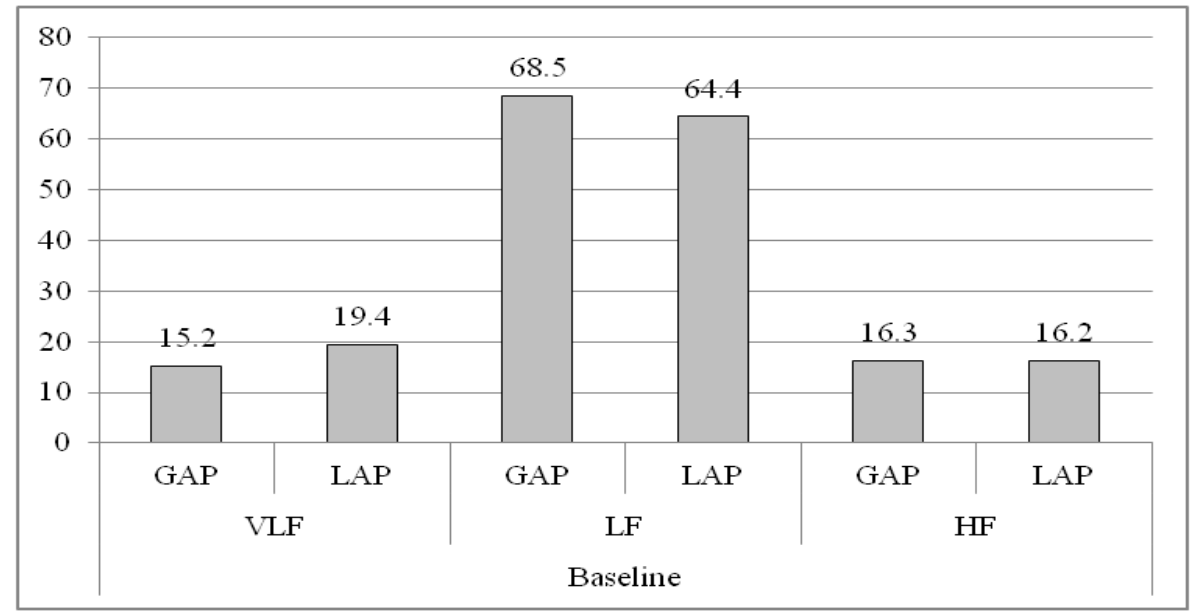

Figure 4.1: Mean values for the baseline protocol among academic performances.

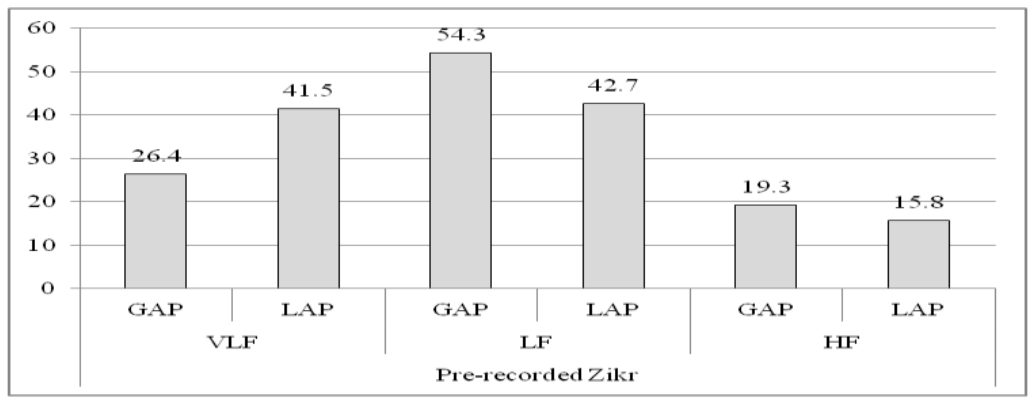

Figure 4.2: Mean values for the Pre-recorded $D z i k r$ protocol among academic performances.

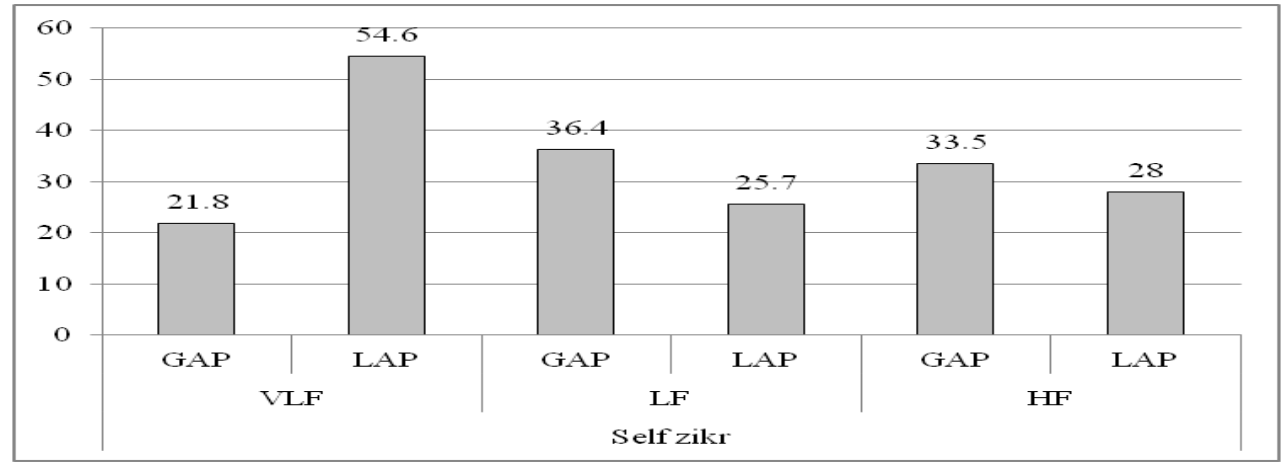

Figure 4.3: Mean values for the Self $D z i k r$ protocol among academic performances.

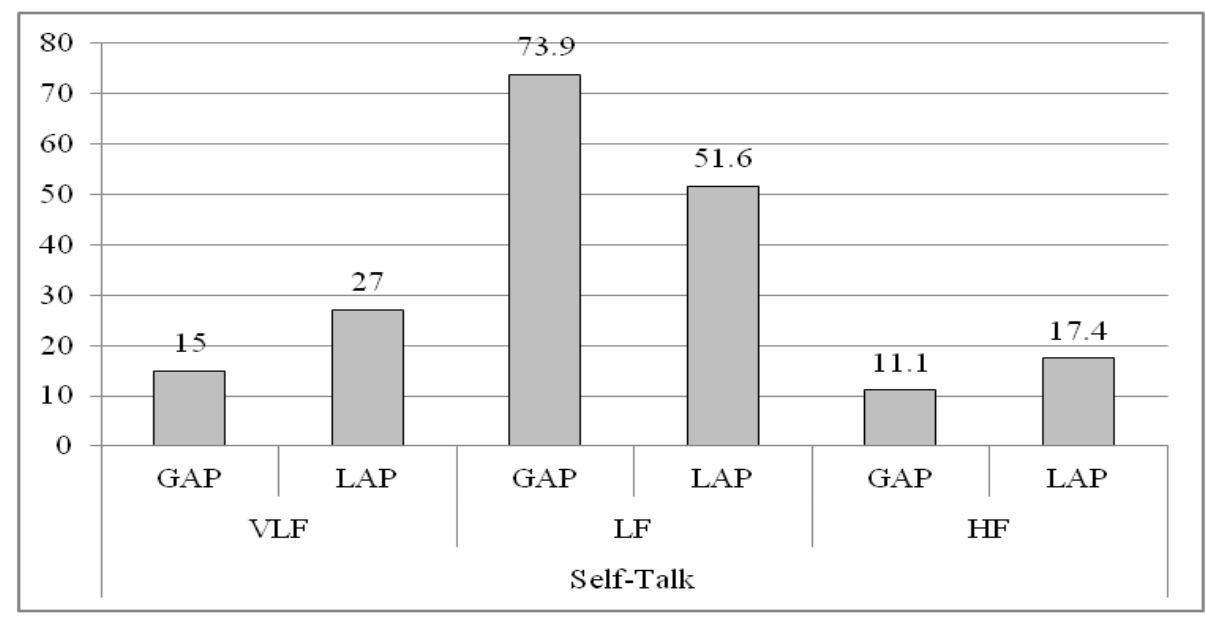

Figure 4.4: Mean values for the Self-Talk protocol among academic performances 
Table 4.7: One Way ANOVA test for differences of VLF, LF and HF between protocols for Good Academic Performances(GAP).

\begin{tabular}{|c|c|c|c|c|c|c|c|c|c|}
\hline $\mathbf{A P}$ & $\mathrm{CS}$ & Protocols & $n$ & Mean & Std. Deviation & Minimum & Maximum & $f$ & $p$ \\
\hline \multirow[t]{12}{*}{$1=\mathrm{GAP}$} & VLF & Baseline & 10 & 15.20 & 19.09 & 0 & 48 & 0.59 & 0.63 \\
\hline & & $\begin{array}{l}\text { Pre-recorded } \\
\text { Zikr }\end{array}$ & 10 & 26.40 & 24.15 & 0 & 73 & & \\
\hline & & Self zikr & 10 & 21.80 & 26.82 & 0 & 72 & & \\
\hline & & Self-Talk & 10 & 15.00 & 20.48 & 0 & 65 & & \\
\hline & LF & Baseline & 10 & 16.30 & 16.52 & 0 & 45 & 1.89 & 0.15 \\
\hline & & $\begin{array}{l}\text { Pre-recorded } \\
\text { Zikr }\end{array}$ & 10 & 19.30 & 12.20 & 0 & 36 & & \\
\hline & & Self zikr & 10 & 33.50 & 37.19 & 0 & 91 & & \\
\hline & & Self-Talk & 10 & 11.10 & 11.90 & 0 & 30 & & \\
\hline & $\mathrm{HF}$ & Baseline & 10 & 68.50 & 33.38 & 18 & 100 & 2.58 & 0.07 \\
\hline & & $\begin{array}{l}\text { Pre-recorded } \\
\text { Zikr }\end{array}$ & 10 & 54.30 & 29.52 & 9 & 100 & & \\
\hline & & Self zikr & 10 & 36.40 & 39.65 & 0 & 100 & & \\
\hline & & Self-Talk & 10 & 73.90 & 28.17 & 17 & 100 & & \\
\hline
\end{tabular}

Notes: $p<0.05$

$\mathrm{AP}=$ Acdemic Performance GAP $=$ Good Academic Performance $\mathrm{CS}=$ Coherence Score

In order to test the differences of VLF, LF and HF in the protocols (Baseline, Pre-recorded Dzikr, Self-Dzikr and SelfTalk) between good and low academic performance, the One Way ANOVA was used.

The ANOVA test indicated that there was no significant difference statistically in the mean value between protocols and the good academic performance (GAP), as shown in Table 4.7. The One Way ANOVA test below was done to test the differences of VLF, LF and HF coherence score among the 10 members of the GAP students. In the VLF coherence score during the Baseline, Pre-Recorded Dzikr, Self-Dzikr and SelfTalk, there were no significant difference statistically in terms of academic performance. The analysis yielded a $f$-ratios value of 0.59 which was not significant at the $0.63(p<0.05)$.

In the LF coherence score, the GAP students indicated that there was no significant difference statistically in terms of academic performance. The analysis yielded a $f$-ratios value of 1.89 which was not significant at the $0.15(p<0.05)$.

Besides that, during the protocols in the clinical experiment, the HF coherence score yielded a $f$-ratios value of 2.58 which was not significant at $0.07(p<0.05)$. Thus, this indicated that the VLF, LF and HF coherence score was

However, in the One Way ANOVA test for the LAP students shown in Table 4.8, it indicates that there was only a significant difference in the VLF $(\mathrm{f}=2.90, \mathrm{p}=0.05)$, where the Self-Dzikr was the highest mean value at 54.60 \pm 37.41 , whereas, the Baseline protocol was the lowest mean value at $19.40 \pm 18.91$.
In the analysis shown in Table 4.8, which explains the comparison among VLF, LF and HF coherence scores with the low academic performance (LAP) students. In the LF coherence score, the analysis yielded a f-ratios value of 1.04 which was not significant statistically at 0.39 ( $p<0.05)$. Besides that, the analysis of the HF coherence score was also not significant statistically at $0.07(\mathrm{p}<0.05)$ with the f-ratios value of 2.62. Table 4.8 indicates that the LAP students failed to implement and adapt the biofeedback training such as diaphragmatic breathing technique and reciting the dzikr into their mind which has been proven could improve performance [27]. It shows that the LAP students failed to achieve satisfied results in the given task. [31]

The methods in the experiment involved the implementation of the self-regulation script in the clinical experiment protocols. The samples were being evaluated on their selfregulation towards the given tasks in different kind of protocols. Thus, their heart rates were being investigated from the baseline until the self-talk protocols. The implementation of diaphragm breathing technique and dzikr recitation with full effort during the protocols would affect their scores in the heart rates readings. The instruments of research consist of questionnaires (DASS questionnaire), biofeedback devices and the clinical experiment involving the sixteen year-old students. In the clinical experiment, the self-regulation stimulation script was being implemented to investigate their achievement goal orientation. 
Table 4.8: One Way ANOVA test for differences of VLF, LF and HF mean between protocols for Low Academic Performances (LAP).

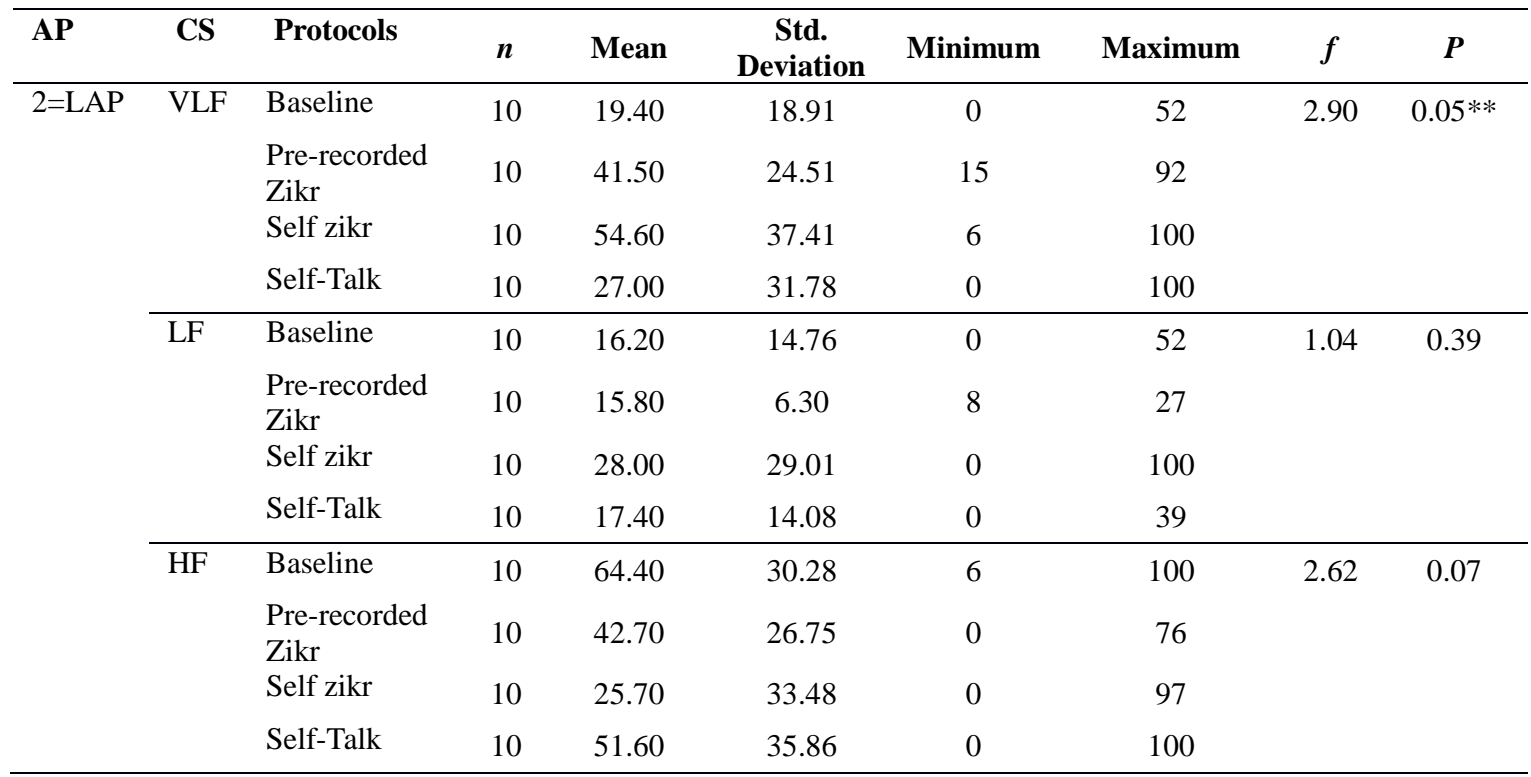

$\mathrm{AP}=$ LAP $=$ Low academic performance $\mathrm{CS}=$ Coherence Score

rated higher score in all protocols compared to the LAP students. They performed well in obtaining the LF score in the baseline, pre-recorded-dzikr, self-dzikr and self-talk protocols. A self-regulated person was reported capable and has the ability in controlling anxiety that directed the person towards the increment in the performance and becomes successful.[32][33] The GAP students who posit higher concentration would lead to a good performance [34]. The person's intend affects his/her performance even when trying to maintain maximum effort [35][36]. Moreover, in a study on procrastination, it was revealed that a procrastinating student has low grades in his/her academic performance due to lack of self-control. [33]

However, the LAP students failed to achieve the target of the clinical experiment by having higher scores in the VLF. The higher scores in the VLF explain a normal breathing in the heart rate variability with 15 to 22 breaths per minute. Meanwhile the target in the clinical experiment was to achieve the 6 breaths per minute which was illustrated in the LF scores. By utilizing the Mann Whitney t-Test and One Way ANOVA test, their scores in the VLF, LF and HF in different protocols were being quantified. The techniques being taught to increase the LF coherence score were the implementation of the slow/diaphragm breathing technique and reciting the the dzikr [37]. A study has approved that the self-regulated students have the ability to control efforts in their way to achieve the targeted goals. Hence, they managed to achieve higher academic performance through goal orientation [38]. However, previous study showed that effort and commitment will arise together with the acceptance of a goal among individuals. Thus, this will affect the feedback and results on the goal performance [29]

\section{CONCLUSION}

Based on the results gathered from the clinical experiment, it was yielded that there were differences statistically on the HRV score between good academic performances (GAP) and low academic performances (LAP). This study had proven that GAP samples were capable in achieving the targeted goal compared to the LAP students. During the clinical experiment, they were being asked to achieve the $100 \%$ LF coherence score or the highest score as they could.

In details, the protocols in this study; baseline, pre-recorded zikr, self-zikr and self-talk were developed with different levels of difficulties. The varieties of difficulties were purposely developed to evaluate their self-regulation in the clinical experiment. It was because a challenging and difficult task might reflect the initial motivation of the samples. Thus, a high level of inner motivation which is one of the criteria in self-regulation is an important element to achieve the targeted goal. The inner motivation towards goal orientation impacted positively on the behavior and performance among students. The ability in adapting the goal orientation in their behavior is shown by the high academic achievers.

It was found that the highest achievement in LF coherence scores resulted from the good academic performance (GAP) students. There was a significant relationship between academic performance and self-regulation which was being proven by this experiment. It is because low academic achievers have less expectation towards success, thus their efforts are not fully mobilized.

The increment in the LF coherence score results indicated that the GAP students achieved higher score in all protocols compared to the LAP students. The targeted goal which was the $100 \%$ LF coherence score had been achieved by the GAP students during the clinical experiment. Thus, the goal orientation had become a motivation in their performance that posits full efforts, persistence and attempted to finish the task successfully.

\section{ACKNOWLEDGMENTS}

This work have been supported under the research grant No. RDU1103101, Universiti Malaysia Pahang, Malaysia. 


\section{REFERENCES:}

[1] Self Regulation, "Tools Of The Mind", www. oolsofthemind.org, (2015)

[2] Steven Stosny, Ph.D, "Psychology Today", www.psychologytoday.com, (2011)

[3] Wikipedia, www.wikipedia.org, (2013)

[4] Cole, P. M., Michel, M. K., \& Teti, L. O, "The development of emotion regulation and dysregulation: A clinical perspective" (Vol. 59, pp.73-100).WileyBlackwell, http://www.jstor.org, (1994).

[5] Thompson, R. A., "Emotion regulation: a theme in search of definition. Monographs for the Society for Research in Child Development", 59, 25e52, (1994)

[6] Niven, K., Totterdell, P., \& Holman, D., "A classification of controlled interpersonal affect regulation strategies". Emotion, 9, 498-509, (2009)

[7] Matt DeLisi. "Chapter 10: Low Self-Control Is a BrainBased Disorder". SAGE Publications Ltd., (2014).

[8] Timpano, K. R.; Schmidt, N. B."The relationship between self control deficits and hoarding: A multimethod investigation across three samples". The Journal of Abnormal Psychology, (2013)

[9] Skinner, B.F., "Science and Human Behavior", p.230, (1953)

[10] Pierce, W. D.; Cheney, C. D., "Behavior Analysis \& Learning. (3rd ed.)". Mahway, New Jersey: Lawrence: Erlbaum Associates. p. 258, (2004).

[11] Butler \& Winne, 1995; Winne \& Perry, (2000); Perry, Phillips, \& Hutchinson, (2006); Zimmerman, (1990); Boekaerts \& Corno, (2005).

[12] Ormrod, Jeanne Ellis, Essentials of Educational Psychology, page 105, Pearson Education Inc., (2009)

[13] Paris, S., Paris, A.. Classroom Applications of Research on Self-Regulated Learning.Educational Psychologist. 36 (2), 89-101, (2001)

[14] Wang, S.L. \& Wu, P.Y., "The role of feedback and selfefficacy on web-based learning: The social cognitive perspective", Computers \& Education. 51(4): 15891598, (2008)

[15] Jang, L.Y. \& Liu, W.C., " $2 \times 2$ Achievement goals and achievement emotions: a cluster analysis of students' motivation", European Journal of Psychology of Education. 27(1): 59-76, (2011)

[16] Bandura, (1977, 1986, 1997)

[17] Kharrazi, A. \& Kareshki, H, "Environmental perceptions, motivational beliefs and self-regulating learning by Iranian high school students. Procedia Social and Behavioral Sciences”, (5): 2160-2164, (2010)

[18] Mohd Rozali Senik and Muhammad Nubli Abdul Wahab, "A pilot study of the effect of zikir on the performance psychology using heart rate variability (hrv)", 4th International Graduate Conference on Engineering, Science \& Huminities (IGCESH ), (2013)

[19] Dr Rosalba Courtney Do Phd, "Breath and Body", www.breathandbody.com.au, (2011)
[20] Mccraty, R.; Atkinson, M.; Tomasino, D. \& Bradley, R.T, "The Coherent Heart Heart - Brain Interactions, Psychophysiological Coherence and the Emergence of System-Wide Order", Integral review. 5(2): 10-114, (2009)

[21] Givvin, K.B.; Stipek, D.J.; Salmon, J.M. \& Macgyvers, V.L., "In the eyes of the beholder: students" and teachers ' judgments of students ' motivation. Teaching and Teacher Education”, (17): 321-331, (2001)

[22] Qi, J.; Mcinerney, D.M.; Arief, G.; Liem, D. \& Ortiga, Y.P. "The relationship between future goals and achievement goal orientations : An intrinsic - extrinsic motivation perspective", Contemporary Educational Psychology, 35(4): 264-279, (2010)

[23] Quigley, K.S. \& Berntson, G.G. , "Autonomic origins of cardiac responses to non-signal stimuli in the rat. Behavioural Neuroscience", (104): 751-762, (1990)

[24] Berntson, G.G. \& Cacioppo, J. T., "Heart Rate Variability: Stress and Psychiatric Conditions" (online), http://psychology.uchicago.edu/people/faculty/cacioppo/j tcreprints/bc04.pdf, 15 May (2013).

[25] Calero, M. D.; García-Martín, M.B.; Jiménez, M.I.; Kazén, M. \& Araque, A. "Self-regulation advantage for high-IQ children: Findings from a research study. Learning and Individual Differences", 17(4): 328-343, (2007)

[26] Kuhl, J. \& Kraska, K. , "Self-regulation: Psychometric properties of a computer-aided instrument" German Journal of Psychology. 71(1): 11-24, (1993)

[27] Sutarto, A.P.; Abdul Wahab, M.N. \& Zain. N., "Heart rate variability (HRV) biofeedback: A new training approach for operator's performance enhancement", Journal of Industrial Engineering and Management. 3(1): 176-198, (2010)

[28] Calero, M. D.; García-Martín, M.B.; Jiménez, M.I.; Kazén, M. \& Araque, A., "Self-regulation advantage for high-IQ children: Findings from a research study. Learning and Individual Differences." 17(4): 328-343, (2007)

[29] Lunenburg, F.C. , "Goal-Setting Theory of Motivation", International of Management, Business, and Administration. 15(1): 1-6, (2011)

[30] Baumeister, R. F.; Bratslavsky, E.; Muraven, M. \& Tice, D. M. "Ego depletion: is the active self a limited resource?" Journal of personality and social lpsychology. 74(5): 1252-1265, (1998)

[31] Vandellen, M.R.; Hoyle, R.H. \& Miller, R., "The Regulatory Easy Street: Self-Regulation Below the SelfControl Threshold Does not Consume Regulatory Resources", Personality and Individual Differences. 52(8): 898-902, (2012)

[32] Zakaria, J.B.; Musib, H.B. \& Shariff, S.M., “Overcoming Performance Anxiety Among Music Undergraduates", Procedia - Social and Behavioral Sciences. 90(2012): 226-234, (2013)

[33] Klassen, R.M.; Krawchuk, L.L. \& Rajani, S., “Academic procrastination of undergraduates: Low self-efficacy to self-regulate predicts higher levels of procrastination", 
Contemporary Educational Psychology. 33(4): 915-931, (2008)

[34] Wilson, V.E.; Peper, E. \& Schmid, A., "Applied Sport Psychology: Personal Growth to Peak Performance", 5th ed. Williams, J.N. (Ed.). Boston: McGraw Hill, (2006)

[35] Latash, M. \& Jaric, S., "Instruction-dependent muscle activation patterns within a two-joint synergy: Separating mechanis from neurophysiology", Journal of Motor Behaviour. (30): 194-198, (1998)

[36] Theodorakis, Y.; Laparidis, K. \& Kioumourtzoglou, E., "Combined effects of goal setting and performance feedback on performance and physiological response on a maximum effort task", Perceptual and Motor Skills. (86): 1035-1041, (1998)
[37] Senik, M.R. \& Abdul Wahab, M.N., "A pilot study of the effect of zikir on the performance psychology using heart rate variability ( hrv )", Proceeding of the 4th International Graduate Conference on Engineering, Science and Humanities (ICGESH) 2013. pp. 10471050, (2013)

[38] Schapiro, S.R. \& Livingston, J.A., "Dynamic SelfRegulation: The Driving Force Behind Academic Achievement", Innovative Higher Education. 25(1): 23 $35,(2000)$

[39] Robbins, J., "Communication and Linguistic Ideology", Current Anthropology. 42(5): 591-614, (2001). 